\title{
Evaluation of normal neurological development of human fetuses from 21 to 30 weeks' gestation through fetal auditory evoked response
}

\author{
Sérgio Hecker Luz ${ }^{1, *}$, Fabiano Candal \\ Vasconcellos' ${ }^{1}$, Tatiana Kreling ${ }^{1}$, Fernanda Silva \\ Pacheco ${ }^{1}$ and Márcia Lorena Fagundes \\ Chaves $^{2}$ \\ ${ }_{1}^{1}$ Department of Gynecology and Obstetrics of Medical \\ School Pontifical Catholic University of Rio Grande do \\ Sul, Rio Grande do Sul, Brazil \\ 2 Department of Intern Medicine of Medical School \\ UFRGS and Medical Sciences Program of \\ Pos-graduation Federal University of Rio Grande do \\ Sul, Rio Grande do Sul, Brazil
}

\begin{abstract}
Objectives: To evaluate the neurological maturation of fetuses between 21 and 30 weeks' gestation by the auditory evoked response.

Methods: The auditory evoked responses of 25 normal singleton fetuses were observed once a week from 21 to 30 weeks' gestation. The stimulus consisted of five pulses of sinusoidal waves, for $2 \mathrm{~s}$, at 1500 cycles/s, with a sound pressure of $125 \mathrm{~dB}$.

Results: Fetal auditory evoked response increased with neurological maturation, presenting two main points of positive discontinuity. The two points in the heart response were detected between the $24^{\text {th }} / 25^{\text {th }}$ and the $27^{\text {th }} / 28^{\text {th }}$ week. From the $27^{\text {th }}$ week on, fetal motor response (FMR) was always present. Initial fetal heart response presented a fluctuation pattern between the $21^{\text {st }}$ and the $30^{\text {th }}$ week, with a tendency to increase as gestational age advanced. Fetal heart response also increased with gestational age. Late response (LR) fluctuated until the $29^{\text {th }}$ week, and was always present after that period.

Conclusions: The maturation of the fetal nervous system is clearly demonstrated by changes in the auditory evoked responses in different gestational ages, and presents some discontinuity points.
\end{abstract}

Keywords: Cardiotocography; central nervous system; cohort studies; evoked potentials, auditory; fetal devel-

\footnotetext{
${ }^{*}$ Corresponding author:

Sérgio Hecker Luz

Felicíssimo de Azevedo 1290

Bairro Auxiliadora

CEP 90540-110 - Porto Alegre

RS, Brazil

E-mail: sergioheckerluz@hotmail.com
}

opment; fetal monitoring; fetal movement; fetus/physiology; neurological examination; pregnancy trimester, second; prospective studies.

\section{Introduction}

The auditory evoked response (AER) of human fetuses to sound has been studied for a long time. Sontag and Wallace, in 1936, two of the pioneers, showed that the response could be observed by two aspects: fetal movement and changes in the fetal heart rate (FHR) [33]. In 1971, Grimwade et al. and Walker et al. determined sound levels in the fetal environment, FHR change, and fetal movement in response to sound and vibration [13, 34]. While studying fetal brain activity, Goodlin et al. applied AER during labor to stimulate quiet fetuses. Goodlin et al. were the first to suggest that AER could be used as a tool to evaluate fetal well-being [11]. Subsequently, other authors also established that AER was a useful tool to evaluate fetal well-being during labor [6, $9,20,22]$.

Luz et al. [21] and Read and Miller [29] also used AER to evaluate fetal well-being during pregnancy at term. Leader et al. studied fetal habituation to AER and found that this test might assess the integrity of the fetal central nervous system (CNS) [15].

Birnholz and Benacerraf concluded that fetal hearing could be tested antenatally, and that the lack of AER to sound stimulus could be caused either by hearing impairment or significant depression of the CNS [1]. Divon et al. established the concept that fetal startle reflex could provide an objective and quantitative estimate of the fetal neurological condition. The startle reflex is a normal response to combined sound-vibratory stimulus after 30 weeks of gestation in healthy infants and consists of a generalized paroxysmal motion that involves the entire body [5]. Pietrantoni [28] and others [10, 12] demonstrated that intermediate and high-frequency sounds are safe to the fetus, whereas low-frequency sounds might induce fetal hearing impairment [10].

The objectives of this study were to evaluate the AER of fetuses between the $21^{\text {st }}$ and $30^{\text {th }}$ week of gestation, as well as observing changes in fetal AER as gestational age advances. We evaluated if the AER of very premature fetuses is similar to that of mature fetuses and applied the standard AER score to very premature fetuses. 


\section{Patients and methods}

We studied 35 non-smoking pregnant women between the $21^{\text {st }}$ and $30^{\text {th }}$ week of gestation cared in São Lucas Hospital pre-natal care unit, PUCRS (Brazil). The number of gestational weeks was determined by the information provided by the last menstrual period or by first trimester ultrasound examination. Subjects were informed about the aims and methods of the study, and gave their informed consent. The study was approved by the Ethical and Scientific Committee of São Lucas Hospital, PUCRS.

The selection criteria were singleton pregnancy, normal fetus, and available dating, The exclusion criteria were use of tobacco, alcohol, or illicit drugs, pre-gestational clinical disease, congenital malformation, chromosomal defects, and non-attendance to any of the clinical exams. Ten mothers were excluded from the study due to the following reasons: six did not attend the clinical examinations, one used illicit drugs, one used tobacco, and two participated in the pilot project. Therefore, final number of subjects included 25 fetuses: 15 male [60\%] and 10 female [40\%]. There were only two premature deliveries, both at 35 weeks' gestation, due to premature rupture of membranes. Average infant birth weight was $3385 \mathrm{~g}$ (range 2480-4415), and each infant had a 5-min Apgar score $\geq 8$. All infants were discharged from hospital after rooming-in with their mothers. Data were collected from May 5, 2001 to 22 December 2002.

Fetuses were stimulated by an EA device (MG\&T, Caxias do Sul, Brazil) that generated five pulses of sinusoidal waves for $2 \mathrm{~s}$ at 1500 cycles/s with a sound pressure of $125 \mathrm{~dB}$ (as measured at a distance of $50 \mathrm{~cm}$ from the sound generator). FHR was monitored using a Hewlett-Packard Cardiotocograph series 50 (Boeblingen, Germany). The ultrasound apparatus used in the study was an ATL Ultramark IV real-time scanner. A videorecording system (VHS) was also used to record the examinations.

The study was carried out from the $21^{\text {st }}$ to the $30^{\text {th }}$ week of gestation, during a quiet state for more than a minute (motor and heart rate) when fetuses were weekly stimulated. A real-time ultrasound examination determined fetal position during maternal semi-recumbent body position. The procedure consisted of applying a sound stimulus on the maternal abdomen, close to the fetal head, observing the fetal response on the ultrasound screen, and recording it on a VCR tape. Mothers also informed whether they felt a fetal motor response (FMR).

There were always at least two researchers monitoring the ultrasound screen in order to determine the occurrence of fetal response to the 5-pulse stimuli. The FHR monitor was used from 5 min before stimulation until FHR return to the initial state. The VCR was activated immediately before the application of the sound stimulus, which lasted around one minute.
Each case was analyzed by one of the authors (SHL). Each examination recorded on VCR tapes was reviewed three times in order to determine FMR. FMR was considered positive when the fetus moved at least one part of the body in association to the stimulus recorded in video. Different types of FMR were identified, including limb, trunk, and head movements. FMR was also determined as Initial or Late Response (LR). Initial fetal motor response was classified as absent, moderate or intense, according to video recordings and maternal information. Startles were considered intense, whereas other responses were classified as moderate. Late fetal motor response (LFMR) was classified as absent or present, being absent when the fetus remained in a quiet state and present when the fetus changed to a motion state.

FHR traces were analyzed according to "Electronic fetal heart rate monitoring research guidelines for interpretation" [7]. Initial fetal heart rate response (IFHRR), maximum fetal heart rate response (MFHRR), duration of fetal heart rate response (DFHRR), and late fetal heart rate response (LFHRR) were also evaluated. IFHRR was the variation of the heart rate immediately before and after the stimulus. Maximal response was the variation between heart rate before stimulus and the highest rate presented during DFHRR after stimulation. A ruler was utilized to aid the interpretation of fetal traces.

Fetal evoked response score was obtained by adding the results of fetal stimulation interpretation previously published and summarized in Table 1 [23]. In general, the score is determined for fetuses near term; however, we chose to observe the same parameters in far-from-term fetuses.

A database was created using Microsoft Excel, and all statistical analyses were performed using SPSS (Statistical Package for Social Sciences). Parametric data were analyzed by Student's $t$-test for independent and dependent variables, or by repeated measure procedure of MANOVA. Non-parametric data were analyzed using Mann-Whitney's test for independent variables, and Wilcoxon's test for variable samples. Categorical variables were analyzed by $\chi^{2}$-test, using, when necessary, Yates' corrections or Fisher's exact test.

\section{Results}

\section{Fetal motor response (FMR)}

Considering all fetuses studied by week of gestation, FMR showed a near linear increase from 21 to 26 weeks, followed by a plateau of full response at 27 weeks and continuing through the last gestational age studied. FMR, when present, was almost a startle, classified as intense

Table 1 Score of the evoked fetal response.

\begin{tabular}{llll}
\hline Variable & Points & & \\
\cline { 2 - 4 } & 0 & 1 & 2 \\
\hline Duration of FHR response & $0-30 \mathrm{~s}$ & $30-350 \mathrm{~s}$ & $>350 \mathrm{~s}$ \\
Initial response FHR & $0-10 \mathrm{bpm}$ & $11-20 \mathrm{bpm}$ & $+20 \mathrm{bpm}$ \\
Maximum response FHR & $0-15 \mathrm{bpm}$ & $16-35 \mathrm{bpm}$ & $+35 \mathrm{bpm}$ \\
Initial fetal motor response & Absent & Moderate & Intense \\
Late response & Absent & Single (CV or motor) & Double (CV +motor)
\end{tabular}

FHR, fetal heart rate; CV, cardiovascular; normal value 6-10; abnormal value 0-5. 
Table 2 Frequency of fetal motor response at each week of gestation, the initial fetal response and response to the total number of stimulus.

\begin{tabular}{llll}
\hline $\begin{array}{l}\text { Week of } \\
\text { gestation }\end{array}$ & $\begin{array}{l}\text { Fetal motor } \\
\text { response } \\
\text { (any stimulus) }\end{array}$ & $\begin{array}{l}\text { Intense } \\
\mathrm{n}(\%)\end{array}$ & $\begin{array}{l}\text { Response to the } \\
\text { total number of } \\
\text { stimulus }\end{array}$ \\
\hline 21 & $16(64 \%)$ & $16(100)$ & $07(28 \%)$ \\
22 & $19(76 \%)$ & $16(84.21)$ & $09(36 \%)$ \\
23 & $20(80 \%)$ & $19(95)$ & $11(44 \%)$ \\
24 & $19(79.2 \%)$ & $18(94.74)$ & $13(54.2 \%)$ \\
25 & $23(88.5 \%)$ & $22(95.65)$ & $14(53.8 \%)$ \\
26 & $24(96 \%)$ & $22(95.65)$ & $18(72 \%)$ \\
27 & $23(100 \%)$ & $21(91.30)$ & $21(91.3 \%)$ \\
28 & $25(100 \%)$ & $22(88)$ & $25(100 \%)$ \\
29 & $25(100 \%)$ & $25(100)$ & $25(100 \%)$ \\
30 & $21(100 \%)$ & $21(100)$ & $21(100 \%)$ \\
\hline
\end{tabular}

and with a fluctuation between 84.21 and $100 \%$ (Table 2).

The first stimulus triggered the onset of FMR in all evaluations. From the $28^{\text {th }}$ week onwards, FMR was observed after all five stimuli (Table 2). In general, the motor response was characterized by intense startle, involving head, arms, trunk, and legs. Legs were not involved in only three evaluations (Table 3).

\section{Cardiovascular response (CVR)}

Considering all fetuses studied per week of gestation, IFHRR showed a near linear increase from 21 to 30 weeks' gestation, a small fluctuation after the $25^{\text {th }}$ week, and an increasing trend proportional to gestational age. Interestingly, on the $22^{\text {nd }}$ week of gestation, the IFHRR was flat and the standard deviation insignificant. ANOVA showed a very significant difference around the $28^{\text {th }}$ week of gestation as compared to all previous gestational ages $(P=0.0001$; Table 4).

\section{Maximum fetal heart rate response (MFHRR)}

Considering all fetuses studied by week of gestation, MFHRR had mild fluctuation at the $22^{\text {nd }}$ week of gesta-
Table 4 Average $( \pm S D)$ of cardiovascular responses.

\begin{tabular}{llll}
\hline $\begin{array}{l}\text { Week of } \\
\text { gestation }\end{array}$ & $\begin{array}{l}\text { Initial } \\
\text { FHR } \\
\text { response } \\
\text { (bpm) }\end{array}$ & $\begin{array}{l}\text { Maximal } \\
\text { FHR } \\
\text { response } \\
\text { (bpm) }\end{array}$ & $\begin{array}{l}\text { Duration } \\
\text { cardiovascular } \\
\text { response } \\
\text { (s) }\end{array}$ \\
\hline 21 & $1.6(4.99)$ & $4.0(5.91)$ & $39.7(82.53)$ \\
22 & $0.6(3.40)$ & $2.8(4.22)$ & $26.6(60.72)$ \\
23 & $1.2(7.81)$ & $4.2(6.90)$ & $89.8(134.59)$ \\
24 & $3.6(6.08)$ & $6.1(7.39)$ & $101.2(107.59)$ \\
25 & $2.8(4.61)$ & $7.3(9.09)$ & $143.0(185.13)$ \\
26 & $4.4(9.97)$ & $10.2(11.38)$ & $172.5(175.05)$ \\
27 & $6.5(9.56)$ & $13.6(10.59)$ & $231.9(173.21)$ \\
28 & $13.6(12.02)$ & $20.7(12.43)$ & $325.0(195.70)$ \\
29 & $12.9(7.06)$ & $23.6(11.91)$ & $371.2(327.07)$ \\
30 & $14.0(8.93)$ & $22.0(10.04)$ & $426.7(246.57)$ \\
\hline
\end{tabular}

FHR, fetal heart rate; bpm, beats per minute.

tion, but a clear tendency to increase as gestational age advanced. ANOVA showed a very significant difference between the $21^{\text {st }}$ and the $26^{\text {th }} / 27^{\text {th }}$ weeks of gestation, $\mathrm{P}=0.0001$. A striking increase occurred from 28 weeks onwards (Table 4).

\section{Duration of response (DR)}

Considering all fetuses studied by week of gestation, DR steadily increased as gestation advanced from the $21^{\text {st }}$ to the $30^{\text {th }}$ week. Two different discontinuity points were observed: the first occurred between the $23^{\text {rd }} / 24^{\text {th }}$ week, and the second at the $28^{\text {th }}$ week of gestation. During that period, DR was equal to that found in a fetus near term. ANOVA showed a very significant difference, beginning on the $27^{\text {th }}$ week, with a more striking difference on the $28^{\text {th }}$ week as compared to earlier gestation, $\mathrm{P}=0.0001$ (Table 4).

\section{Late response (LR)}

Late response to fetal stimulation was evaluated as an association of the motor and cardiovascular responses. Considering all fetuses studied by week of gestation, there was a fluctuation between the $21^{\text {st }}$ and the $30^{\text {th }}$

Table 3 Weeks of gestation $X$ type and initial fetal motor response.

\begin{tabular}{|c|c|c|c|c|c|c|}
\hline \multirow{2}{*}{$\begin{array}{l}\text { Week of } \\
\text { gestation }\end{array}$} & \multicolumn{6}{|c|}{ Type of fetal motor response } \\
\hline & $\mathrm{L}+\mathrm{A}+\mathrm{T}+\mathrm{H}$ & $\mathrm{L}+\mathrm{A}+\mathrm{T}$ & $\mathrm{L}+\mathrm{T}+\mathrm{H}$ & $L+A$ & $\mathrm{~L}+\mathrm{T}$ & $\mathrm{A}+\mathrm{T}$ \\
\hline 21 & 7 & 4 & 3 & 1 & 1 & \\
\hline 22 & 10 & 3 & 5 & - & 1 & \\
\hline 23 & 4 & 5 & 7 & 4 & - & \\
\hline 24 & 7 & 4 & - & - & 8 & \\
\hline 25 & 11 & 4 & 5 & 1 & 2 & \\
\hline 26 & 14 & 1 & 5 & 1 & 2 & 1 \\
\hline 27 & 12 & 2 & 8 & 1 & - & \\
\hline 28 & 20 & 1 & 1 & 2 & - & 1 \\
\hline 29 & 20 & - & 3 & 1 & - & 1 \\
\hline 30 & 18 & - & - & 3 & - & \\
\hline
\end{tabular}

L, legs; A, arms; T, trunk; $H$, head. 
Table 5 Late response by weeks of gestation.

\begin{tabular}{llll}
\hline $\begin{array}{l}\text { Week of } \\
\text { gestation }\end{array}$ & \multicolumn{3}{l}{ Late response } \\
\cline { 2 - 4 } & Absent 0 & $\begin{array}{l}\text { Single } \\
\text { (Motor or CV) 1 }\end{array}$ & $\begin{array}{l}\text { Double } \\
\text { (Motor +CV) 2 }\end{array}$ \\
\hline 21 & $8(32.0 \%)$ & $15(60 \%)$ & $02(8 \%)$ \\
22 & $7(28.0 \%)$ & $12(48 \%)$ & $05(20 \%)$ \\
23 & $6(24.0 \%)$ & $11(44 \%)$ & $08(32 \%)$ \\
24 & $3(12.5 \%)$ & $11(45.8 \%)$ & $10(41.7 \%)$ \\
25 & $2(7.7 \%)$ & $14(53.8 \%)$ & $10(38.5 \%)$ \\
26 & $0(0 \%)$ & $08(32 \%)$ & $17(68 \%)$ \\
27 & $0(0 \%)$ & $06(26.1 \%)$ & $17(73.9 \%)$ \\
28 & $0(0 \%)$ & $03(12 \%)$ & $22(88 \%)$ \\
29 & $0(0 \%)$ & $00(0 \%)$ & $25(100 \%)$ \\
30 & $0(0 \%)$ & $01(4.8 \%)$ & $20(95.2 \%)$ \\
\hline
\end{tabular}

$\mathrm{CV}$, cardiovascular response.

Table 6 Score by week of gestation.

\begin{tabular}{ll}
\hline Week of gestation & Score \\
\hline 21 & $2.44(1.80)$ \\
22 & $2.40(1.87)$ \\
23 & $3.20(2.00)$ \\
24 & $3.58(1.88)$ \\
25 & $3.92(1.83)$ \\
26 & $5.08(1.86)$ \\
27 & $5.65(1.96)$ \\
28 & $6.56(2.16)$ \\
29 & $7.00(1.38)$ \\
30 & $7.19(1.60)$ \\
\hline
\end{tabular}

week of gestation, and the response tended to double as gestational age advanced. From the $29^{\text {th }}$ week onwards, both responses (motor + cardiovascular) were observed (Table 5).

The score used for fetuses near term was applied for far-from-term fetuses, with an increase of two discontinuous points being observed. The first increase was observed between the $23^{\text {rd }}$ and the $25^{\text {th }}$ week of gestation. The second, which was more evident, was observed on the $26^{\text {th }}$ week of gestation. After that period, the increase was proportional to gestational age (Table 6).

\section{Discussion}

Divon et al. considered fetal startle reflex as an objective and quantitative fetal neurological trait [5]. Other authors also studied the maturation of fetal response as gestational age advanced $[4,8,9,23,27]$. Birnholz and Benacerraf studied fetal response between the 16 and 32 weeks' gestation, and stated 'that a sharp transitional occurrence of auditory startle behavior at the $25^{\text {th }}$ week of gestation frontier of extrauterine viability provides an additional indicator of neuromotor maturity that may be applied in clinical practice" [1]. In the present study, we analyzed fetal response between 21 and 30 week's ges- tation in order to evaluate maturational changes to an evoked auditory response through motor and cardiovascular responses.

We showed that IFMR between 64 and $96 \%$ on the $21^{\text {st }}$ and $26^{\text {th }}$ week. From the $27^{\text {th }}$ week of gestation onwards, a motor response was always present. MANOVA showed a very significant difference on the $27^{\text {th }}$ week of gestation as compared to all other previous gestational ages $(P<0.0001)$. This may be a point of neurological maturation of human fetuses to evoked auditory stimulation.

Considering the 244 exams performed, the type was available in 215 [88.11\%] exams and was classified as a startle, in most cases, with leg movement in all instances, except for three. Indeed, the whole fetal response to sound stimulation is complex and may involve a variety of movements (eyes, eyelids, mounting, breathing, swallowing, and urination). Data obtained in this study enabled the evaluation of the movement of limbs, trunk, and head.

DiPietro et al. found that fetal body movements, which accelerate FHR, increased from 21 to $57 \%$ between the $20^{\text {th }}$ week and term, while the latency or lag time between FM onset and FHR change decreased from 5.0 to $2.7 \mathrm{~s}$ during the same period. In most cases, the onset of FM precedes FHR change. As the fetus matures, the relation between FM and FHR becomes increasingly synchronized and temporarily associated in healthy fetuses. FHR changes at the beginning of the movement, as opposed to the end suggesting that FHR acceleration and FM may both be initiated and maintained by the intensity of neural innervations [3]. Data obtained in the present study are consistent with DiPietro's findings. As gestation advances, fetuses show a more intense and constant AER to sound stimulation in all determined parameters. According to different authors, even using different methodologies, the change from quiet to active state is the most consistent determinant of FHR acceleration. Thus, FM and FHR become increasingly integrated as gestation advances [2-4, 14, 17, 18].

Another interesting aspect related to motor response is that in almost all cases it consists of a startle involving the legs. The stimulation was delivered to the fetus when in a quiet behavior. No statistically significant difference was observed in fetal late motor response until the $26^{\text {th }}$ week of gestation, when all fetuses changed from a quiet to an active behavior.

Initial FHR response increased as gestational age advanced, with a significant difference around the $27^{\text {th }}$ week. The duration of LR was significantly different with a clear turning point at the $26^{\text {th }}$ week of gestation. DiPietro et al. showed a $100 \%$ acceleratory response to vibroacoustic stimulation on the $28^{\text {th }}$ week of gestation [2]. The discontinuation point of IFHRR at 22 weeks' gestation could be explained by the cochlear development paradox showing an inverse localization of response to 
low frequency sound if compared to adult cochlea. This event could represent the turning point of this paradox but needs confirmation by other researchers [25, 27].

The values of the parameters included in the score proposed by Luz et al. to determine near-term fetal wellbeing were very high for the far-from-term fetuses [23]. However, our results showed that far-from-term fetuses presented a clear increase of fetal auditory evoked response after the $28^{\text {th }} / 29^{\text {th }}$ week of gestation. During that period, their auditory response was similar to that of near-term fetuses.

Habituation, another form of accessing maturation of the fetal CNS, did not occur in our study. Two important points should be stressed. First, the fetus was stimulated once a week, a long period for the far-from-term fetus to retain the stimulus information; second, the stimulus had only five pulses, with very short intervals (2 s), which did not allow measurement of habituation [15].

Near-term fetuses in a state of well-being show exuberant AER [16, 19, 20, 22-24, 26, 27, 29-32]. Our results confirm that far-from-term fetuses can also show an exuberant evoked response. The auditory evoked response of these fetuses was not uniform and changed as the CNS matured. This is clearly demonstrated by the changes in all parameters evaluated by the AER and has direct association with fetal age.

Although the score reached a mean value of 6.56 at 28 weeks' gestation, that represents an intermediary zone of normality to near-term fetuses, the standard to be used for far-from-term fetuses needs to be redefined, as well as the interpretation of the cardiotocographic traces when fetuses are $<32$ weeks' gestation [7].

We conclude that fetal AER accompanies the maturation of the fetal CNS, the standard values used for score determination of fetal AER need to be defined for farfrom-term fetuses and that fetal AER between the $28^{\text {th }}$ and $30^{\text {th }}$ week of gestation became similar to that of nearterm fetuses.

\section{References}

[1] Birnholz JC, Benacerraf BR. The development of human fetal hearing. Science. 1983;222:516-8.

[2] DiPietro JA, Hodgson DM, Costigan KA, Hilton SC, Johnson TR. Fetal neurobehavioral development. Child Dev. 1996;67:2553-67.

[3] DiPietro JA, Hodgson DM, Costigan KA, Hilton SC, Johnson TR. Development of fetal movement - fetal heart rate coupling from 20 weeks through term. Early Hum Dev. 1996;44:139-51.

[4] DiPietro JA, Irizarry RA, Hawkins M, Costigan KA, Pressman EK. Cross-correlation of fetal cardiac and somatic activity as an indicator of antenatal neural development. Am J Obstet Gynecol. 2001;185:1421-8.

[5] Divon MY, Platt LD, Cantrell CJ, Smith CV, Yeh SY, Paul $\mathrm{RH}$. Evoked fetal startle response: a possible intrauterine neurological examination. Am J Obstet Gynecol. 1985;153: 454-6.

[6] Edersheim TG, Hutson JM, Druzin ML, Kogut EA. Fetal heart rate response to vibratory acoustic stimulation predicts fetal pH in labor. Am J Obstet Gynecol. 1987;157: 1557-60.

[7] Electronic fetal heart rate monitoring: research guidelines for interpretation. National Institute of Child Health and Human Development Research Planning Workshop. Am J Obstet Gynecol. 1997;177:1385-90.

[8] Gagnon R, Hunse C, Carmichael L, Fellows F, Patrick J. Human fetal responses to vibratory acoustic stimulation from twenty-six weeks to term. Am J Obstet Gynecol. 1987;157:1375-81.

[9] Gagnon R, Hunse C, Carmichael L, Patrick J. Vibratory acoustic stimulation in 26- to 32-week, small-for-gestational-age fetus. Am J Obstet Gynecol. 1989;160:160-5.

[10] Gerhardt KJ. Prenatal and perinatal risks of hearing loss. Semin Perinatol. 1990;14:299-304.

[11] Goodlin RC, Schmidt W. Human fetal arousal levels as indicated by heart rate recordings. Am J Obstet Gynecol. 1972;114:613-21.

[12] Griffiths SK, Pierson LL, Gerhardt KJ, Abrams RM, Peters AJ. Noise induced hearing loss in fetal sheep. Hear Res. 1994;74:221-30.

[13] Grimwade JC, Walker DW, Bartlett M, Gordon S, Wood C. Human fetal heart rate change and movement in response to sound and vibration. Am J Obstet Gynecol. 1971;109: 86-90.

[14] Groome LJ, Mooney DM, Holland SB, Smith LA, Atterbury JL, Dykman RA. Behavioral state affects heart rate response to low-intensity sound in human fetuses. Early Hum Dev. 1999;54:39-54.

[15] Leader LR, Baillie P, Martin B, Vermeulen E. Fetal habituation in high-risk pregnancies. $\mathrm{Br} \mathrm{J}$ Obstet Gynaecol. 1982;89:441-6.

[16] Lengle JM, Chen M, Wakai RT. Improved neuromagnetic detection of fetal and neonatal auditory evoked responses. Clin Neurophysiol. 2001;112:785-92.

[17] Lecanuet JP, Granier-Deferre C, Busnel MC. Fetal cardiac and motor responses to octave-band noises as a function of central frequency, intensity and heart rate variability. Early Hum Dev. 1988;18:81-93.

[18] Lecanuet JP, Schaal B. Fetal sensory competencies. Eur J Obstet Gynecol Reprod Biol. 1996;68:1-23.

[19] Luz NP. Auditory evoked response of the human fetus: simplified methodology. J Perinat Med. 1991;19:177-83.

[20] Luz NP. Auditory evoked responses in the human fetus. II. Modifications observed during labor. Acta Obstet Gynecol Scand. 1985;64:213-22.

[21] Luz NP, Behle I, Luz SH. Comparison between auditory evoked responses and oxytocin challenge test in the prenatal evaluation of the human fetus in high-risk pregnancies. Abstracts IX World Congress of Gynecology and Obstetrics-FIGO-Tokyo contribution. 1979;843:367.

[22] Luz NP, Lima CP, Luz SH, Feldens VL. Auditory evoked responses of the human fetus. I. Behavior during progress of labor. Acta Obstet Gynecol Scand. 1980;59:395-404.

[23] Luz NP, Luz SH, Medaglia Filho PV, Hessel RS, Gonçalves MAG. Resposta auditiva provocada como método de avaliação fetal: novos critérios de interpretação. Rev Bras Ginecol Obstet. 1984;6:47-54.

[24] Miller DA. External stimuli. Clin Obstet Gynecol. 2002; 45:1054-62. 
[25] Peck JE. Development of hearing. Part II. Embryology. J Am Acad Audiol. 1994;5:359-65.

[26] Pereira LN, Pereira LC, Germany PL, Hecker LJ. Auditory evoked response: a new approach for the evaluation of the unborn fetus. Reproduccion. 1980;4:255-63.

[27] Pierson LL, Gerhardt KJ, Griffiths SK, Abrams RM. Auditory brainstem response in sheep. Part I: Fetal development. Dev Psychobiol. 1995;28:293-305.

[28] Pietrantoni M, Arango H, Looney SW, Stockard JE, Parsons MT, Spellacy WN. Vibroacoustic stimulation and auditory acuity in preterm infants. J Matern Fetal Med. 1995;4:144-8.

[29] Read JA, Miller FC. Fetal heart rate acceleration in response to acoustic stimulation as a measure of fetal well being. Am J Obstet Gynecol. 1977;129:512-7.

[30] Sohmer H, Freeman S. Functional development of auditory sensitivity in the fetus and neonate. J Basic Clin Physiol Pharmacol. 1995;6:95-108.
[31] Sohmer H, Freeman S. The pathway for the transmission of external sounds into the fetal inner ear. J Basic Clin Physiol Pharmacol. 2001;12:91-9.

[32] Sohmer H, Geal-Dor M, Weinstein D. Human fetal auditory threshold improvement during maternal oxygen respiration. Hear Res. 1994;75:145-50.

[33] Sontag L, Wallace RF. Changes in the rate of the human fetal heart in response to vibratory stimulus. Am J Dis Child. 1936;51:583-9.

[34] Walker D, Grimwade J, Wood C. The acoustic component of the fetal environment. J Reprod Fertil. 1971;24:125-6.

The authors stated that there are no conflicts of interest regarding the publication of this article.

Received June 10, 2008. Revised October 15, 2008. Accepted November 7, 2008. Previously published online February 6, 2009. 